\title{
REPRESENTAÇÃO ESTUDANTIL NO ENSINO SUPERIOR: A POLÍTICA DE PARTICIPAÇÃO DISCENTE NOS DEPARTAMENTOS DE ENSINO DA FACULDADE DE FILOSOFIA, CIÊNCIAS E LETRAS DE SÃO JOSÉ DO RIO PRETO (1957 A 1964).
}

\author{
REPRESENTACIÓN ESTUDIANTIL EN LA ENSEÑANZA SUPERIOR: LA \\ POLÍTICA DE PARTICIPACIÓN DISCENTE EN LOS DEPARTAMENTOS DE \\ ENSEÑANZA DE LA FACULTAD DE FILOSOFÍA, CIENCIAS Y LETRAS DE \\ SÃO JOSÉ DO RIO PRETO (1957 A 1964).
}

\begin{abstract}
STUDENT REPRESENTATION IN HIGHER EDUCATION: THE POLITICS OF STUDENT PARTICIPATION IN THE TEACHING DEPARTMENTS OF THE FACULTY OF PHILOSOPHY, SCIENCES AND LETTERS OF SÃO JOSÉ DO RIO PRETO (1957 TO 1964).
\end{abstract}

\author{
Silvana Fernandes LOPES $^{1}$ \\ Nathanael da Cruz e Silva NETO ${ }^{2}$
}

RESUMO: Este artigo faz parte de uma investigação mais ampla cujo objetivo é a reconstrução da história da Faculdade de Filosofia, Ciências e Letras de São José do Rio Preto (FFCL). Por meio da pesquisa documental (atas departamentais), discutimos a atuação discente nos departamentos da instituição no período de 1957 a 1964, ou seja, do início das atividades da FFCL até o Golpe Civil-Militar de 1964, que modificou fortemente o funcionamento do ensino superior em geral, e o dessa instituição em particular. Mesmo considerando os limites impostos pela utilização exclusiva de fontes documentais, com este estudo, foi possível inferir a "qualidade" da participação dos alunos, ou seja, o quanto os estudantes interferiam, de fato, em algumas questões de organização da FFCL e, por outro lado, os limites dessa participação.

PALAVRAS-CHAVE: Faculdade de Filosofia. Ciências e Letras (FFCL). Política educacional brasileira. Representação estudantil.

RESUMEN: Este artículo parte de una investigación más amplia cuyo objetivo es la reconstrucción de la historia de la Facultad de Filosofía, Ciencias y Letras de São José do Rio Preto (FFCL). Por medio de investigación documental (actas departamentales), discutimos la actuación discente en los departamentos de la institución en el periodo de 1957 a 1964, o sea, del inicio de las actividades de la FFCL hasta el Golpe Civil-Militar de 1964, que modificó fuertemente el funcionamiento de la enseñanza superior en general, y de esa institución en particular. Aunque se consideren los límites impuestos por la utilización exclusiva de fuentes documentales, con este estudio, fue posible inferir la "calidad" de la participación de los alumnos, o sea, cuanto los estudiantes realmente interferían, en algunas cuestiones de organización de la FFCL y, por otro lado, los límites de esa participación.

\footnotetext{
${ }^{1}$ Doutora em Educação. Departamento de Educação do Instituto de Biociências, Letras e Ciências Exatas de São José do Rio Preto (IBILCE) e Programa de Pós-Graduação em Educação da Faculdade de Filosofia e Ciências de Marilia (FFC). Email: silvanaflopes@gmail.com

${ }^{2}$ Mestrando em Educação. Programa de Pós-Graduação em Educação da Faculdade de Filosofia e Ciências de Marília (FFC). Email: ncsilvaneto@gmail.com
} 
PALABRAS CLAVE: Facultad de Filosofía. Ciencias y Letras (FFCL). Política educacional brasileña. Representación estudiantil.

ABSTRACT: This paper is part of a more extensive research aimed at reconstructing the history of Faculty of Philosophy, Sciences and Languages of São José do Rio Preto (FFCL). Through documentary research (departmental minutes), we discuss the student performance in the departments of the institution from 1957 to 1964, ie from the beginning of the activities of FFCL to the Civil-Military Coup of 1964 that strongly modified the functioning of education and of this institution. Even considering the limitations imposed by the exclusive use of documentary sources, it was possible to infer the "quality" of the participation of students, i.e., how much students interfered, in fact, in some organizational matters of FFCL and, furthermore, the limits of such participation.

KEYWORDS: Faculty of Philosophy. Sciences and Letters (FFCL). Brazilian educational policy. Student representation.

\section{Introdução}

O presente trabalho faz parte de uma investigação mais ampla cujo objetivo é a reconstrução da história da Faculdade de Filosofia, Ciências e Letras de São José do Rio Preto (FFCL). Elegemos como recorte cronológico para este estudo o período compreendido ente 1957 a 1964, por abranger desde o início das atividades da FFCL até o Golpe Civil-Militar de 1964, que modificou fortemente o funcionamento do ensino superior em geral, e o dessa instituição em particular.

O desenvolvimento das forças produtivas de São José do Rio Preto, que a destacou, na época, como importante centro econômico do noroeste paulista, acelerou o processo de urbanização da região na década de 1950, período no qual a FFCL foi criada. A esta altura, a cidade já contava com uma população predominantemente urbana. Assim, aliando interesses de políticos locais e de membros das camadas mais escolarizadas, estavam dadas as condições para se criar uma instituição de ensino superior na cidade.

Contudo, é importante observar que a criação da FFCL não foi uma iniciativa isolada. O ensino superior vinha crescendo desde o período imperial, e nas décadas de 1950 e 1960 essa expansão aumentou consideravelmente, em função da aceleração do desenvolvimento urbano-industrial e da forte pressão exercida pelas camadas médias. Dentro desse quadro, a fundação dos Institutos Isolados de Ensino no interior do estado de São Paulo foi uma das estratégias da política educacional para procurar atender tanto 
as necessidades de desenvolvimento econômico quanto os anseios das camadas médias em busca de ascensão social via título superior.

De acordo com Cunha (2007), durante a república populista (1945 a 1964), o ensino superior apresentou um crescimento acentuado e integrado, só modificado a partir do Golpe de 1964.

As universidades, no sentido estrito, passaram de cinco, em 1945, para 37, em 1964. O número de estabelecimentos isolados subiu de 293 para 564, nesse período. Enquanto o número de universidades foi multiplicado por sete, o de escolas isoladas não chegou a dobrar. As universidades não nasceram tais, sendo formadas pela integração de escolas isoladas, as mudanças quantitativas criando condições para mudanças qualitativas; quando essas escolas atingiam certo número, em uma determinada cidade, agregavam-se em universidades, polarizadas por um vínculo institucional. Foi o caso das nove universidades católicas. No setor público, quando esse vínculo não existia, o governo federal o providenciou através das "federalizações" de faculdades estaduais e particulares (CUNHA, 2007, p. 205).

Nesse contexto, os Institutos Isolados de Ensino Superior do estado de São Paulo foram constituídos por 16 faculdades: Faculdades de Filosofia, Ciências e Letras de Araraquara, Assis, Franca, Marília, Presidente Prudente, Rio Claro, Ribeirão Preto e São José do Rio Preto; Faculdade de Agronomia e Medicina Veterinária de Jaboticabal; Faculdades de Farmácia e Odontologia de Araçatuba, Araraquara e São José dos Campos; Faculdade de Odontologia de Botucatu; Faculdade de Engenharia de Guaratinguetá e Faculdade de Música Maestro Julião, de São Paulo. Praticamente todos esses cursos foram aglutinados, em 1976, quando o Governo Estadual, por meio da Lei Estadual $n^{\circ}$ 952, criou a Universidade Estadual Paulista "Júlio de Mesquita Filho" (UNESP). Esta incorporou a FFLC de São José do Rio Preto, alterando seu nome para Instituto de Biociências, Letras e Ciências Exatas.

A Faculdade de Filosofia, Ciências e Letras de São José do Rio Preto foi criada em 1955 - iniciando seu funcionamento dois anos depois -, em um processo que contou com a participação de diversas associações de classe, tais como as de Medicina e Cirurgia, a Comercial, Industrial e Agrícola, a Rural, a Regional de Odontologia, a Profissional dos Contabilistas, a dos Engenheiros, a dos Farmacêuticos; além do Rotary Clube, do Lyons Clube e da Seção Local da Ordem dos Advogados. Posteriormente, tais associações compuseram o Conselho Geral da FFCL.

A Lei Municipal no 394, de 26 de maio de 1955, que criou a Universidade Municipal de São José do Rio Preto, previa, em suas disposições gerais e finais, a 
possibilidade de o estado encampá-la. Em 1956, foi submetida à Assembleia Legislativa do Estado de São Paulo a proposta de lei $n^{\circ} 602 / 56$, na qual se pleiteava a criação de uma FFCL na cidade como um Instituto Isolado do Sistema Estadual de Ensino Superior. O projeto foi vetado pelo Governador (Mensagem $\mathrm{n}^{\circ}$ 144, de 04 de abril de 1957), mas a Assembleia Legislativa rejeita o veto, aprovando a Lei $n^{\circ} 3.844$, de 10 de maio de 1957: "Fica criada na cidade de São José do Rio Preto, como instituto isolado do sistema estadual de ensino superior, uma Faculdade de Filosofia, Ciências e Letras" (LODI, 1976; 1977).

Suas atividades foram iniciadas em 1957, constituindo-se em uma instituição de ensino superior importante para a cidade e para a região em seu entorno. Os primeiros cursos em funcionamento na FFCL foram os de Letras Anglo-Germânicas, Letras NeoLatinas, História Natural e Pedagogia, organizados em três departamentos de ensino: Letras, História Natural e Pedagogia.

De acordo com a bibliografia disponível (Attab, 1973; Oliveira, 1989; Silva, 1995; Vaidergorn, 1995), o projeto educacional proposto pela FFCL de São José do Rio Preto foi bastante inovador se comparado aos demais Institutos Isolados de Ensino Superior do interior paulista. As principais características que teriam conferido a essa instituição um papel de vanguarda foram a organização em departamentos, a paridade na representação estudantil e o desenvolvimento de atividades extracurriculares envolvendo a comunidade de São José do Rio Preto e região.

Em contrapartida, baseando-se na análise da organização departamental e da representação discente durante o período de 1957 a 1964, Lopes \& Sparvoli (2013) concluíram que a originalidade do projeto educacional foi superdimensionada pela bibliografia produzida, contribuindo para reforçar uma visão idealizada dessa instituição. Os resultados indicaram que ela foi organizada em departamentos, porém coexistindo com o regime de cátedra. Já no que diz respeito à representação estudantil, esta funcionou de maneira diferente no interior da instituição, isto é, paritária no departamento de Pedagogia e restrita a um aluno por série nos departamentos de Letras e de História Natural.

Durante o período estudado, os estudantes da FFCL participaram de forma ativa das atividades desenvolvidas pelo movimento estudantil em âmbito nacional, viabilizaram trabalhos em parceria com professores dos departamentos de Letras e Pedagogia, tais como o Grupo Universitário de Trabalhos Artísticos e o projeto de alfabetização de adultos, este vinculado ao Movimento de Cultura Popular. 
Uma condição indispensável para a viabilização da proposta educacional da FFCL seria a participação estudantil nas instâncias decisórias da FFCL. Por isso, é interessante verificar como se dava, de fato, essa participação. Nesse sentido, o presente estudo objetiva discutir a atuação discente nos departamentos da FFCL de São José do Rio Preto no período de 1957 a 1964.

\title{
Questões teórico-metodológicas no estudo de instituições escolares
}

Podemos enquadrar este estudo na história das instituições escolares. Assim como qualquer instituição, as escolares são constituídas pela síntese de múltiplas determinações e cada uma responde a essas determinações de uma forma particular, produzindo sua identidade.

No interior das instituições há um quebra-cabeça a ser decifrado. Uma vez dentro da instituição, trata-se de se fazer o jogo das peças em busca dos seus respectivos lugares. Legislação, padrões disciplinares, conteúdos escolares, relações de poder, ordenamento do cotidiano, uso dos espaços, docentes, alunos e infinitas outras coisas ali se cruzam (SANFELICE, 2007, p. 77).

Cabe, então, ao investigador, do ponto de vista metodológico, buscar apreender essa identidade na relação entre o particular e o geral. Se, por um lado, para a compreensão de uma instituição é fundamental que seja evidenciada a sua relação com o contexto econômico, político, social e cultural que a produziram, por outro,

\begin{abstract}
A singularidade de uma determinada instituição societária exprime os seus elementos internos (constituição jurídica, objetivos sociais, representações políticas etc.) que a distinguem das outras instituições e são, por conseguinte, exclusivos dessa instituição e não de outra qualquer (BITTAR \& FERREIRA JR., 2009, p. 501).
\end{abstract}

Nesse sentido, entendemos que há diferentes caminhos possíveis para a investigação da história de uma instituição escolar e, no caso deste estudo, focalizamos um dos aspectos relevantes: os seus estudantes.

[...] um eixo importante de articulação das análises [das instituições escolares] será dado pelo público-alvo. Ou seja, trata-se de formular a questão: a quem se destina a instituição que estou me propondo a reconstruir e que resultados ela pretende atingir com a ação empreendida? A busca de informações sobre o alunado será, pois, um elemento importante na reconstrução histórica das instituições 
escolares, uma vez que, além de ajudar na definição do perfil institucional, trará, também, indicações importantes sobre sua relevância social (SAVIANI, 2007, p. 25).

Todavia, convém considerar aqui que a eleição das fontes sempre dependerá, em maior ou menor grau, das condições materiais objetivas de acesso, constituindo-se num dos limites impostos para a investigação da história de uma instituição escolar. Isso porque as mudanças trazidas pelo tempo estão, aos poucos, destruindo os suportes dessa memória. Prédios e objetos são substituídos e deixados de lado, documentos deterioramse ou são descartados por falta de cuidados e espaço e as reminiscências pessoais desaparecem junto com seus portadores. Surdamente, as ligações com o passado tornam-se quase invisíveis.

Em busca de vencer tais dificuldades, a reconstrução da história da Faculdade de Filosofia, Ciências e Letras de São José do Rio Preto - objetivo da investigação na qual este trabalho está inserido - tomou como ponto de partida os documentos recuperados com o desenvolvimento de projetos de estruturação e preservação do arquivo histórico da instituição, que culminou, mais recentemente, com a organização do "Centro de Documentação e Memória do IBILCE"3. Desse conjunto de documentos, para este estudo em particular, foram utilizadas como fontes as "Atas das Reuniões Ordinárias e Extraordinárias do Departamento de Letras" (1959-1963) e as “Atas das Reuniões do Conselho do Departamento do Curso de História Natural” (1961-1963).

Por fim, é de fundamental importância salientar que as atas são fontes de informações extremamente ricas, mas, como todo documento oficial, elas podem ter sido profundamente distorcidas na sua produção, especialmente por razões de ordem político-institucional. Cabe ao pesquisador, portanto, examiná-las tendo em conta essas limitações.

\section{A atuação discente nos departamentos de ensino da FFCL}

De acordo com Oliveira (1989), o novo modelo universitário proposto pela FFCL seria a organização em departamentos, uma novidade em termos de estrutura, uma vez que as universidades se organizavam a partir de cátedras vitalícias. Entretanto,

${ }^{3}$ O projeto original, intitulado "Organização do Centro de Documentação e Memória do IBILCE - $1^{\mathrm{a}}$ fase: diagnóstico documental”, foi realizado no ano de 2010, sob coordenação da Profa. Dra. Silvana Fernandes Lopes e financiamento da Reitoria da UNESP. 
assim como em diversas outras universidades e institutos, registrou-se a coexistência entre cátedra e departamento. Somente com a lei de estadualização $\mathrm{n}^{\circ} 5.177$, de 13 de janeiro de 1959, é que se dispôs oficialmente que "para melhor realização de suas atividades didáticas e científicas, as Cadeiras se articularão em Departamentos [...]” (SÃO PAULO, 1959, p. 8).

Nesse contexto, o departamento de Letras foi fundado oficialmente em 24 de agosto de 1959, de acordo com a "Ata da Reunião Preliminar" e a "Ata da Reunião de Fundação" (FACULDADE DE FILOSOFIA, CIÊNCIAS E LETRAS, 1959-1963). Os estudantes participaram das reuniões desde o início, já ocupando o cargo de secretárioarquivista e integrando a comissão de redação do anteprojeto do departamento.

Realizou-se, a seguir, a eleição do Chefe, Vice-Chefe e do SecretárioArquivista do Departamento.

Foram eleitos Chefe: o Prof. Norman M. Potter, Vice-Chefe: o Prof. Carlos de Assis Pereira, Secretária-arquivista: Srta. Elena Olga M. Andreoli à qual foi, ato contínuo, transmitida a função de secretariar a sessão.

Tratou-se então, da data da $1^{\text {a }}$ Reunião Ordinária, que ficou marcada para 12 de Setembro, constando a ordem do dia, da discussão dos trabalhos extra-curriculares, nomeando-se os prof. Orestes Nigro e Flavio V. Di Giorgi para redigir o ante-projeto pertinente [do regimento interno do departamento], e ainda Srta. Elena Andreoli e Newton de Oliveira (FACULDADE DE FILOSOFIA, CIÊNCIAS E LETRAS, 1959-1963, p. 3).

A questão da representação estudantil começou a ser discutida já a partir da primeira reunião ordinária, realizada no dia 12/09/1959.

Na parte do expediente, à sugestão do Prof. Di Giorgi sugere de que os alunos organizassem seu estatuto mínimo regulando suas relações com o Departamento, ajuntou o prof. Orestes Nigro a de que, a cada representante de classe fosse distribuída uma cópia do edital de convocação de cada reunião futura, devendo ser a seguir assinada pela classe; ao aparte do Sr. Prof. Norman M. Potter, segundo o qual os alunos devem organizar-se como entendam, o Sr. Prof. Orestes Nigro concordou, reafirmando o caráter de sugestão da providência indicada (FACULDADE DE FILOSOFIA, CIÊNCIAS E LETRAS, 19591963, p. 3).

Também é interessante verificar a forma como a discussão vai sendo encaminhada pelos docentes. Em 05/04/1960, data da segunda reunião extraordinária, na qual só estavam presentes os professores, ficou decidido que a representação seria de 
um aluno para cada classe dos dois cursos, totalizando, então, oito representantes discentes.

Passou-se a discutir o problema da participação dos alunos no Departamento de Letras, tendo sido apresentada as seguintes propostas:

1) Prof. Pinto de Carvalho, "dois alunos representantes com voto consultivo".

2) Prof. Guillermo de la Cruz Coronado, "2 (dois) alunos representantes com voto deliberativo".

3) Prof. Orestes Nigro: "voto deliberativo, qualquer que seja o número de representantes".

4) Por votação foi aceita a proposta do sr. prof. Flavio V. Di Giorgi: "8 alunos um representante de cada classe dos cursos de Letras, com voto deliberativo", que dentre 9 votos obteve 5 votos favoráveis.

Tratou-se então dos fins do Dep. de Letras, que corresponderiam tacitamente ao que foi expôsto na lei estadual. Tendo sido feita a leitura da lei pelo Chefe de Departamento, foi discutida a questão da legalidade da participação dos alunos com valor deliberativo. Foi aprovada a interpretação dada à lei pelo Departamento, no sentido de considerar-se legal a referida participação (FACULDADE DE FILOSOFIA, CIÊNCIAS E LETRAS, 1959-1963, p. 8-9).

Já no dia 20/04/1960, na reunião seguinte, a qual contava novamente com a presença exclusiva de docentes, a decisão quanto ao número de representantes discentes foi revista. Observe-se que o tema voltou ao debate por iniciativa do mesmo autor da proposta vencedora na reunião realizada quinze dias antes.

3) O prof. Flávio Vespasiano di Giorgi propôs a reabertura da discussão relativa à representação dos alunos no Departamento, encaminhando à Mesa proposta no sentido dessa representação ser feita através de 4 (quatro) alunos, um representante de cada uma das séries dos cursos de Letras. À pergunta do prof. Antonio Pinto de Carvalho sôbre as razões que o levaram a apresentar nova proposta, disse o prof. Flávio Vespasiano di Giorgi que considerara o seguinte:

a) o número de votantes vencidos ao ser aprovada sua proposta indicava uma divisão séria no Departamento;

b) de modo nenhum 8 (oito) representantes havia sido um número irretratável;

c) seria bom que os alunos representassem séries e não classes.

Uma $2^{\text {a }}$ proposta foi apresentada pelo prof. Orestes Nigro: " 4 alunos, um representante de cada uma das classes de $3^{\circ}$ e $4^{\circ}$ anos dos cursos de Letras".

Em votação nominal, obtiveram as duas propostas o seguinte resultado:

a) proposta do prof. Flávio Vespasiano di Giorgi: 5 votos favoráveis.

b) proposta do prof. Orestes Nigro: 2 votos favoráveis. Houve abstenção de três votos (FACULDADE DE FILOSOFIA, CIÊNCIAS E LETRAS, 1959-1963, p. 10). 
Por conta dessa decisão, a representação estudantil no departamento de Letras ficou sendo a de um aluno por série para cada um dos cursos durante todo o período abrangido por este trabalho. Esse número foi mantido a despeito das inúmeras reivindicações por paridade encaminhadas pelo Diretório Acadêmico e por meio da greve estudantil realizada em $1962^{4}$. Não obstante, da análise das atas é possível apreender que os alunos representantes participavam ativamente nas reuniões departamentais.

Em termos gerais, os alunos fizeram parte de uma série de comissões, tais como a do regimento interno do departamento, como já mencionado anteriormente, a da elaboração do horário e do calendário escolar, a da discussão de propostas de atividades extraclasses a serem organizadas, entre outras.

Também chama a atenção o número expressivo de comissões formadas pelo departamento para estudo de temas específicos e formulação de propostas a serem votadas em plenário. Contudo, a morosidade com que os resultados dessas comissões são apreciados em plenário, estendendo-se geralmente por muitas reuniões, é notória.

Ainda que seja evidente a deficiência na sistemática de organização dos trabalhos do departamento, muitas vezes a responsabilidade pela lentidão no processo tendia a recair sobre os alunos. No trecho que se segue é possível evidenciar tal fato.

O prof. Orestes, presidente da Comissão da Reforma de Currículo informou à casa que estava aguardando sugestões dos alunos para a elaboração do trabalho. Manifestou estranheza pelo desinterêsse dos alunos por um assunto tão importante, pois apenas alguns haviam entregue [sic] à Comissão sugestões. Sugere que a Casa delegue à Comissão poderes para elaborar, mesmo sem colaboração de outros membros, o Anteprojeto de Reforma do Currículo. A aluna Mary Leite de Barros esclareceu que não foi por falta de interêsse sôbre o assunto que os alunos haviam se ausentado do problema, mas por se julgarem ainda mal-informados a respeito da reforma e que gostariam de discutir o problema no Departamento, ao que o Prof. Orestes respondeu que isso viria a influir na opinião dos discentes. O Prof. Orestes pede que se coloque o problema da delegação de poderes à Comissão para elaborar o Anteprojeto. A aluna Nari Nagamine sugere que se promova na Faculdade conferências e debates sôbre a questão da reforma do currículo. Voltando à proposta do Prof. Orestes, foi

${ }^{4}$ Essa greve teve duração de quase três meses (de final de junho a agosto de 1962), deflagrada pela União Nacional dos Estudantes (UNE) em razão da sanção da LDB (Lei no 4024/61), na qual se previa que a participação estudantil se daria na forma dos estatutos das universidades e escolas isoladas. Na tentativa de impedir que as instituições, isoladamente, optassem pelo menor número possível de alunos representantes ou pela limitação de sua atuação, os estudantes reivindicaram um terço de representação em todos os órgãos colegiados. Embora tivesse uma longa duração, a greve não obteve o resultado esperado. 
submetido à votação e aprovada (FACULDADE DE FILOSOFIA, CIÊNCIAS E LETRAS, 1959-1963, p. 52).

Ainda assim, a opinião dos alunos no âmbito das comissões parece ter sido, na maior parte das vezes, razoavelmente acolhida pelos docentes.

No entanto, quando se tratava de críticas mais diretamente endereçadas aos professores, a situação era outra. São recorrentes reclamações quanto ao andamento das atividades letivas: solicitavam pontualidade e assiduidade dos professores no cumprimento das aulas, apresentavam avaliações elaboradas pelo conjunto dos alunos apontando o não cumprimento do programa de algumas disciplinas e a prática do "improviso" no ensino por parte de alguns docentes, reclamavam da excessiva suspensão do período letivo, comprometendo o conteúdo a ser ensinado, entre outros problemas.

Destacamos, então, alguns exemplos mais representativos dessas críticas e dos seus encaminhamentos durante as reuniões.

Aberta a sessão [...] passou-se ao expediente que constou de:

I- Uma solicitação da srta. Maria Maria Aparecida Abelaria, representante da $3^{\mathrm{a}}$ série do curso de Neolatinas, para que se tomassem medidas visando uma melhor observância do Horário de aulas, por parte de alguns professores.

Levantou-se um debate de que participaram os seguintes aparteantes:

a) Sr. Prof. Orestes Nigro solicitando melhor exposição do problema e de sua gravidade.

b) o Sr. Zequi Elias, representante da $1^{\text {a }}$ série do curso de Neolatinas, que tomou a si esta exposição alegando não ser justo que o aluno seja privado do intervalo maior entre as aulas pois isto implica num atraso geral em relação às aulas posteriores.

c) Prof.a Maria Edith do A. Garboggini, endossando a alegação do Sr. Zequi Elias acrescentou que é prejudicial também para os professores.

d) O sr. prof. Orestes Nigro, que a título de justificação, atribuiu esta inobservância do Horário à liberdade com que se têm realizado os trabalhos nesta Faculdade, levando em conta principalmente a boa intenção do professor.

e) Prof. Edoardo Querin que observou ser, o Horário, uma lei e como tal, deve ser respeitado rigorosamente (FACULDADE DE FILOSOFIA, CIÊNCIAS E LETRAS, 1959-1963, p. 5-6).

A questão da pontualidade voltou a ser pauta na reunião seguinte:

Aberta a sessão, lida, discutida e aprovada a ata, passou-se ao Expediente em que o Sr. Prof. Guillermo de La Cruz Coronado solicitou que se exigisse aos alunos a mesma observância ao horário que se exigia aos senhores professores (FACULDADE DE FILOSOFIA, CIÊNCIAS E LETRAS, 1959-1963, p. 7v). 
A necessidade de formulação de um calendário escolar era o tema mais frequentemente apresentado pelos alunos. Porém, fica claro que, embora tivesse sido pauta de dezenas de reuniões departamentais, o calendário escolar não foi instituído durante o período analisado neste trabalho.

O trecho abaixo evidencia não apenas a situação, como também o teor das discussões sobre o assunto ao longo das atas.

Na Ordem do Dia, foi lido pelo Chefe do Departamento um ofício enviado pelos alunos do Curso de Letras Neo-Latinas, referente aos trabalhos de aproveitamento das diversas Cadeiras do Curso, ofício esse contendo as seguintes solicitações:

1) que os professores reunidos façam um calendário em que sejam regulamentados o número racional e as datas de entrega de todos os trabalhos práticos para a nota de aproveitamento";

2) "que a data da entrega dos trabalhos seja marcada até um mês antes dos exames, ficando outrossim esclarecido que nenhum trabalho deverá ser marcado depois daquela data, afim de que os alunos possam preparar suas provas parciais".

$$
[\ldots]
$$

O Chefe do Departamento lembrou aos presentes que:

1) a Chefia do Departamento já tentara fazer um calendário dos trabalhos, sem encontrar suficiente apoio no plenário;

2) a solução do problema só se daria havendo unanimidade dos professores;

3) um calendário geral deveria ser organizado, bem como o entrosamento dos programas.

O Prof. Orestes Nigro propôs que, inicialmente, por questão de princípio, fôsse aprovada a planificação dos trabalhos.

O Prof. Flávio Vespasiano di Giorgi lembrou à Casa as dificuldades de uma tal planificação, desejando também deixar claro os seguintes itens:

1) de modo algum a planificação significaria uma fuga dos trabalhos por parte dos alunos;

2) a referida planificação também não implicaria numa abdicação do método de cada professor.

$$
[\ldots]
$$

Falando em nome dos colegas, a aluna Mary Leite de Barros afirmou que o pedido dos alunos tivera origem no desejo de uma distribuição melhor dos trabalhos pelas Cadeiras e não na vontade de fugir a responsabilidades (FACULDADE DE FILOSOFIA, CIÊNCIAS E LETRAS, 1959-1963, p. 19-20).

Frente a tais críticas, até mesmo os professores considerados mais progressistas contrapunham-se aos alunos, utilizando como principais argumentos a inexperiência dos mesmos para avaliar seus docentes, a fragilidade dos conhecimentos com que ingressaram no ensino superior e o não cumprimento de seus deveres acadêmicos. 
A situação dos alunos de História Natural mostrava-se ainda mais frágil. Em termos de representação estudantil, é inegável que a greve de 1962 na FFCL de São José do Rio Preto acabou por trazer maior impacto sobre os alunos de História Natural. Ao passo que os estudantes de pedagogia já tinham paridade e os de letras lutavam por ela, a obtenção de um terço de representação para os alunos de História Natural, de acordo com a reivindicação em âmbito nacional, significaria um expressivo avanço.

\begin{abstract}
Antes da referida greve, na FFCL a representação estudantil no departamento de Letras era de um aluno por série para cada um dos cursos (Letras Anglo-Germânicas e Letras Neo-Latinas) e no departamento de História Natural era de apenas um aluno. Como resultado da greve, o recém-formado Conselho do Departamento de História Natural aprovou a representação de um aluno por série, "o menor número possível", de acordo com a ata do Conselho dos Departamentos do Curso de História Natural, de 09 de abril de 1962 (LOPES \& SPARVOLI, 2013, p. 290).
\end{abstract}

Da análise das atas desse departamento, depreende-se que, apesar de a representação discente ter aumentado para um aluno por série, os estudantes não tinham voz ativa nas questões discutidas, raramente constando nos registros dessas atas. Vale ressaltar aqui que os representantes discentes frequentavam assiduamente as reuniões e participavam de inúmeras comissões formadas pelo departamento, uma vez que constam os seus nomes nas atas. Todavia, suas possíveis ou eventuais falas quase nunca aparecem registradas.

Dentre os poucos indícios de manifestação dos alunos estão os trechos abaixo, da reunião realizada no dia 21/05/1963, destacados aqui por exemplificarem um "esboço" de atuação discente e a forma de encaminhamento pelos professores do departamento de História Natural.

\footnotetext{
A hora aprazada, o sr. Presidente abre a sessão e faz uma relação os assuntos a serem debatidos no Conselho, que são os seguintes: [...]

2- Ofício da $2^{\mathrm{a}}$ serie, solicitando Horário para sabatinas, redução de aulas no sábado e estudo do regime de promoção; [...] 9- Ofício da $3^{\mathrm{a}}$ série sobre regime de promoção [...]

[...]

Pede a palavra o Prof. Fahad para considerar que todos os assuntos podem ser reduzidos a uns poucos que podem ser discutidos em comissões, com a devida urgência (FACULDADE DE FILOSOFIA, CIÊNCIAS E LETRAS, 1961-1963, s.n.).
}

Com isso, os ofícios contendo reivindicações formuladas pelos alunos saíram da pauta e não mais apareceram ao longo das atas. Ainda assim, na mesma reunião, além 
desses dois pontos de pauta haviam 12 outros. Entre eles, a aceitação ou não de um aluno excedente não foi só discutida como também ocupou a maior parte da reunião. A respeito desse assunto, o representante discente Adail Vetorazzo opinou:

O Conselheiro Adail manifesta-se, dizendo que a esta altura do ano não há vantagem na entrada do aluno, mas acha que para êle será interessante, se não frequentar e trancar a matricula. Evitará assim fazer novo exame vestibular. (FACULDADE DE FILOSOFIA, CIÊNCIAS E LETRAS, 1961-1963, s.n.).

Apesar disso, a proposta foi recusada:

O Sr. Presidente põe em votação a proposta [de aceitação do aluno excedente], que obtém 4 votos a favor e 4 contra, empatando a votação. O Sr. Presidente desempata, dando o voto de Minerva contrário à proposta. Assim é rejeitada a proposta do Prof. Fahad pelo voto de Minerva (FACULDADE DE FILOSOFIA, CIÊNCIAS E LETRAS, 1961-1963, s.n.).

\section{Considerações Finais}

Visando colaborar com a reconstituição da história da Faculdade de Filosofia, Ciências e Letras de São José do Rio Preto, este artigo procurou discutir a atuação discente nos departamentos da instituição no período de 1957 a 1964. Para isso, tomamos como objeto de análise a participação estudantil nos departamentos de Letras e de História Natural.

Mesmo considerando os limites impostos pela utilização exclusiva de fontes documentais - neste caso as atas departamentais -, julgamos que foi possível inferir a "qualidade" da participação dos alunos, ou seja, o quanto os estudantes interferiam, de fato, em algumas questões de organização da FFCL e, por outro lado, os limites dessa participação.

Os estudantes tiveram uma atuação bastante expressiva em diferentes comissões, tais como as da elaboração do calendário escolar e do horário, a do regimento interno do departamento, e das que organizavam as atividades extraescolares.

Por outro lado, foi possível depreender que, mesmo inseridos em um grupo de professores que procurava viabilizar uma proposta mais progressista, como era o caso do de Letras, quando os alunos os questionavam, apontando as falhas na estrutura e no encaminhamento dos cursos, o tratamento era outro. Nesse caso, os argumentos 
fartamente utilizados eram de que os estudantes não tinham experiência e conhecimento para avaliar os docentes. Dessa forma, o "espírito de corporação" se materializava nos departamentos e está presente até os dias de hoje nas relações de poder dentro da universidade.

Por último, cabe-nos lembrar que a participação estudantil não se restringia apenas à atuação nos departamentos da FFCL. Por meio do Centro Acadêmico de Filosofia (CAF), os estudantes estavam articulados em diversas mobilizações, inclusive de âmbito nacional. É o caso, por exemplo, da Campanha de Defesa da Escola Pública, em 1959, uma das mobilizações nacionais mais marcantes do período estudado, deflagrada a partir do "Manifesto dos Educadores", contra o substitutivo apresentado por Carlos Lacerda durante a tramitação da primeira Lei de Diretrizes e Bases da Educação Nacional. Além deste, registrou-se que os estudantes colaboraram ativamente na campanha de estadualização da faculdade.

\section{REFERÊNCIAS}

ATTAB, Z. A. (1973). A experiência da Reforma Universitária na Faculdade de Filosofia, Ciências e Letras de São José do Rio Preto (1959-1964). 106f. Tese (Doutorado em Educação) - Faculdade de Filosofia, Ciências e Letras de São José do Rio Preto, São José do Rio Preto.

BITTAR, M.; FERREIRA JR., A. (2009). História, epistemologia marxista e pesquisa educacional brasileira. Educação \& Sociedade, São Paulo: Cortez; Campinas: Centro de Estudos Educação e Sociedade (CEDES), 107 (30).

CUNHA, L. A. A universidade crítica: o ensino superior na república populista. 3. ed. São Paulo: Editora UNESP, 2007.

FACULDADE DE FILOSOFIA, CIÊNCIAS E LETRAS. Atas das Reuniões do Conselho dos Departamentos do Curso de História Natural. São José do Rio Preto, 1961-1963. 2 v. (não paginados). Depositado na Secretaria do Departamento de Biologia do Instituto de Biociências, Letras e Ciências Exatas, Universidade Estadual Paulista, São José do Rio Preto.

. Atas das Reuniões Ordinárias e Extraordinárias do Departamento de Letras. São José do Rio Preto, 1959-1963. Depositado na Secretaria do Departamento de Estudos Linguísticos e Literários do Instituto de Biociências, Letras e Ciências Exatas, Universidade Estadual Paulista, São José do Rio Preto.

LOPES, S. F.; SPARVOLI, L. P. A Faculdade de Filosofia, Ciências e Letras de São José do Rio Preto (FFCL) no período de 1957 a 1964: estudo de uma instituição escolar. In: SILVA, J. C.; ORSO, P. J.; CASTANHA, A. P.; MAGALHÃES, L. D. (Orgs.). 
História da Educação: arquivos, instituições escolares e memória histórica. Campinas: Alínea, 2013.

OLIVEIRA, N. R. Sapere Aude: a Faculdade de Filosofia, Ciências e Letras de São José do Rio Preto no período de 1957-1964. 1989. 231f. Dissertação (Mestrado em Educação) - Centro de Educação e Ciências Humanas da Universidade Federal de São Carlos, São Carlos, 1989.

SAVIANI, D. Instituições escolares no Brasil: conceito e reconstrução histórica. In: NASCIMENTO, M. I. M.; SANDANO, W.; LOMBARDI, J.C.; SAVIANI, D. (Orgs.). Instituições escolares no Brasil: conceito e reconstrução histórica. Campinas: Autores Associados: HISTEDBR; Sorocaba: UNISO; Ponta Grossa: UEPG, 2007.

SANFELICE, J. L. História das Instituições Escolares. In: NASCIMENTO, M. I. M.; SANDANO, W.; LOMBARDI, J.C.; SAVIANI, D. (Orgs.). Instituições escolares no Brasil: conceito e reconstrução histórica. Campinas: Autores Associados: HISTEDBR; Sorocaba: UNISO; Ponta Grossa: UEPG, 2007.

SÃO PAULO (Estado). Lei no 5177, de 13 de janeiro de 1959. Dispõe sobre aquisição, por doação, de patrimônio da Faculdade Municipal de Filosofia, Ciências e Letras, e sobre a organização didática e administrativa de instituto estadual congênere, criado pela Lei $\mathrm{n}^{\circ}$ 3.844, de 10 de maio de 1957, na mencionada cidade. Diário Oficial [do] Estado de São Paulo, Poder Executivo, São Paulo, S. P., 15 jan. 1959. Seção 1, Ano LXIX, n. 11.

SÃO PAULO (Estado). Lei no 952, de 30 de janeiro de 1976. Cria a Universidade Estadual Paulista "Júlio de Mesquita Filho" e dá providências correlatas. Diário Oficial [do] Estado de São Paulo, Poder Executivo, São Paulo, S. P., 31 jan. 1976. Seção 1, Ano LXXXVI, n. 21.

\section{Como referenciar este artigo}

LOPES, Silvana Fernandes.; NETO, Nathanael da Cruz e Silva. Representação estudantil no ensino superior: a política de participação discente nos departamentos de ensino da Faculdade de Filosofia, Ciências e Letras de São José do Rio Preto (1957 a 1964). Revista Ibero-Americana de Estudos em Educação, Araraquara, v. 11, n. 4 p. 2219-2233, 2016. Disponível em: 〈http://dx.doi.org/10.21723/riaee.v11.n4.8876>. EISSN: 1982-5587.

Submetido em: agosto/2016

Aprovação final em: novembro/2016 